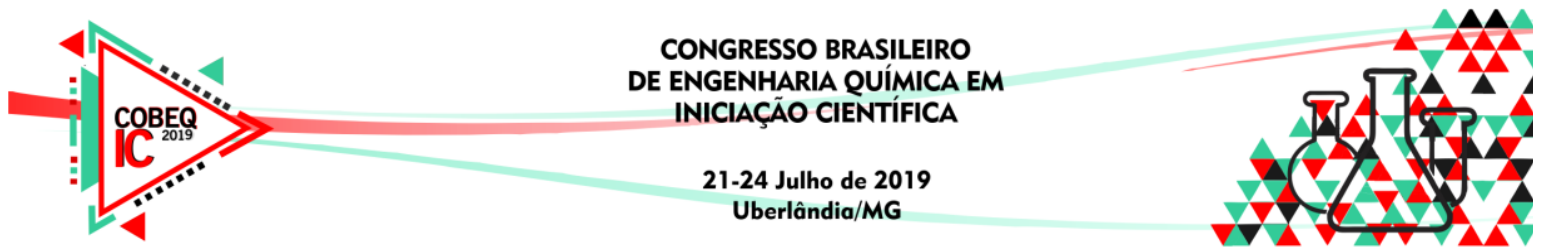

\title{
AMOSTRAGEM E AVALIAÇÃO DAS CARACTERÍSTICAS FÍSICAS E QUÍMICAS DO MATERIAL PARTICULADO NA REGIÃO CENTRAL DO ESTADO DE SÃO PAULO
}

\author{
DONATO, G. M. ${ }^{1}$, COELHO S. G. ${ }^{1}$, CARDOSO, A.A. ${ }^{2}$, THEODOROVIC, A. ${ }^{1}$, \\ COSTA M. A.M. ${ }^{1}$ \\ ${ }^{1}$ Universidade Estadual Paulista, Departamento de Bioquímica e Química Tecnológica \\ ${ }^{2}$ Universidade Estadual Paulista, Departamento de Química Analítica
}

\begin{abstract}
RESUMO - O objetivo desse estudo foi analisar materiais particulados com tamanho de até $2,5 \mu \mathrm{m}$, através da distribuição, concentração mássica e composição iônica e relacionar suas características com trajetórias de massas de ar e focos de queima de biomassa na região de Araraquara (SP). Na amostragem foi usado um impactador de cascata de Andersen e o material foi analisado gravimetricamente e por cromatografia. Essa caracterização possibilitou associar atividades antropológicas com a qualidade do ar na região.
\end{abstract}

\section{INTRODUÇÃO}

Considera-se poluente atmosférico toda substância presente no meio sendo capaz de causar danos à saúde humana, fauna e flora. Esses poluentes, em sua maioria, são provenientes de ações antropológicas (Fogarin, 2018). De acordo com a Organização Mundial da Saúde, mais de 4 milhões de mortes foram causadas por poluição atmosférica. No ano de 2018, conforme a União de Indústria de Cana de Açúcar (UNICA), quase 600 mil toneladas de cana de açúcar foram processadas para produção de açúcar e etanol, somente na região Centro-Sul do país. Um dos aspectos preocupantes sobre essa produção é a queima de biomassa (cana de açúcar) como combustível industrial, emitindo poluentes atmosféricos, como material particulados e compostos gasosos. Material Particulado (MP) é definido como todo material sólido ou líquido suspenso na atmosfera (CETESB, 2019). A composição química do particulado está diretamente relacionado com sua fonte emissora, assim como seu tamanho. Assim, caracterizando o material por concentração e composição pode-se indicar possíveis fontes e ainda, antecipar possíveis efeitos devido à sua toxicidade (Fogarin, 2018). Áreas abertas, em que ocorre a queima de biomassa apresentam caraterísticas na atmosfera em relação à composição química das partículas presentes na mesma, como a acidez mais elevada (Fogarin, 2018). De acordo com Rocha et al (2005), durante os períodos de queima, a concentração de acetato, formiato, cloreto, nitrato, sulfato e oxalato em partículas menores é maior em relação a outros períodos, assim como apresentam uma concentração menor de ânions. Os íons potássio, magnésio e cálcio quando caracterizados em material particulado grosso indicam ressuspensão do solo, mas o potássio também pode indicar a queima de biomassa em partículas finas (Allen, 2004). A presença de amônio nessa mesma faixa de tamanho de partícula também seria um 


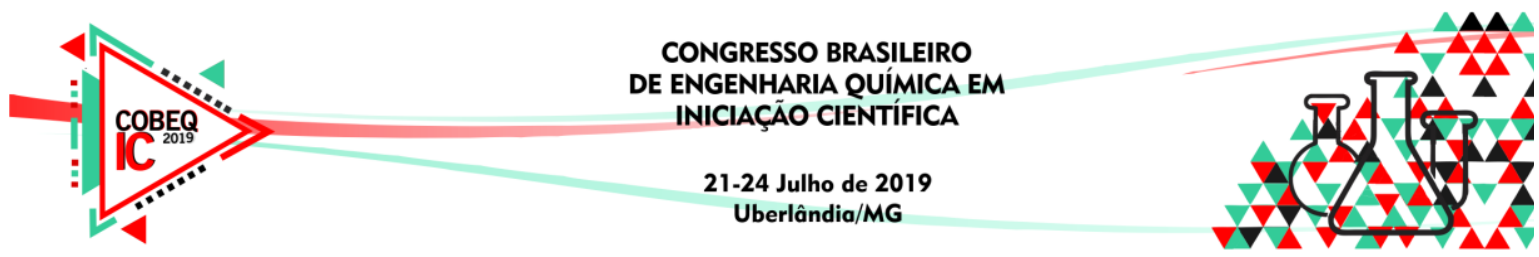

indicador uma vez que há correlação entre a formação do íon e a neutralização dos ácidos provenientes da queima, provocando o aumento dos íons acetato, formiato e oxalato em PM grosso (Souza, 2016).

Logo, observa-se a importância da análise física do material particulado, uma vez que é necessário associar a composição da partícula e o tamanho da mesma. O tamanho do material particulado pode ser analisado pelo diâmetro aerodinâmico, onde se é considerado não somente a geometria do material mas também a densidade e a forma. Esse método possibilita descrever o comportamento da partícula (Vincent, 2007).

\section{OBJETIVO}

O objetivo desse estudo foi avaliar presença de material particulado na atmosféricas e suas possíveis fontes. O estudo apresenta análise física e química de material particulado menor que $2,5 \mu \mathrm{m}$ presente na atmosfera da cidade de Araraquara, São Paulo, Brasil.

\section{MATERIAIS E MÉTODOS}

O material foi coletado nos meses de Setembro e Outubro de 2018 na cidade de

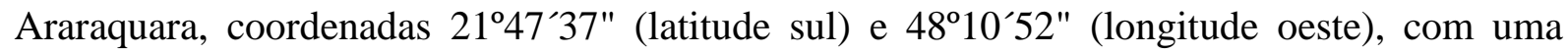
altitude média de 646 metros em relação ao nível do mar. O local de amostragem foi o Campus da Faculdade de Ciências e Letras da Unesp de Araraquara, endereço Rodovia Araraquara-Jaú, $\mathrm{Km} 1$, zona rural do município. Esse material foi caracterizado por tamanho e concentração com o uso de um coletor impactador de cascata de Andersen com oito estágios. O método usado para avaliar a deposição de material no impactador foi a variação de massa dos filtros presentes no interior do mesmo. Além disso, o material também foi analisado por cromatografia gasosa para detectar os íons solúveis presentes nos filtros. O impactador de cascata de Andersen usado tem oito estágios e um filtro de backup. Cada estágio corresponde à uma faixa de tamanho de partícula. As partículas maiores são depositadas no primeiro estágio. As menores seguem o fluxo passando pelos orifícios do Impactador. Esses orifícios diminuem até o último estágio, onde as partículas menores que $0,4 \mu \mathrm{m}$ são depositadas.

\section{RESULTADOS E DISCUSSÃO}

Com a análise gravimétrica dos filtros, obteve-se as massas de material particulado nos estágios para os seguintes dias de amostragem (12/09, 13/09, 19/09, 26/09,01/10 e 03/10). Com esses dados construiu-se o gráfico abaixo (Figura 1). Já as Figuras 2, 3, 4 e 5 representam a trajetória das massas de ar e os focos de queimada no estado de São Paulo de 7/09 à 13/09, $14 / 09$ à 20/09, 21/09 à 27/09 e 28/09 à 3/10 respectivamente.

Para todas as amostragens realizadas observou-se que a concentração de material de particulado e sua composição iônica são influenciadas pelos focos de queimadas e trajetória de massas de ar, uma vez que mesmo não havendo queima de biomassa próximo ao local de amostragem, as massas de ar contribuíram para a composição da mesma. 


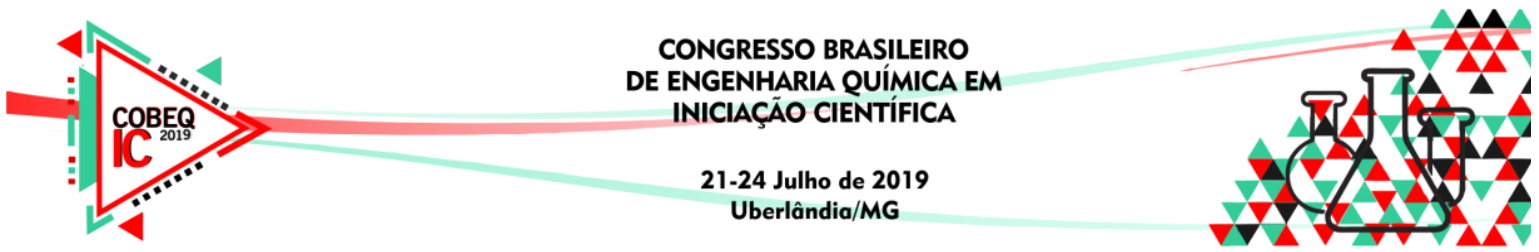

Figura 1: Gráfico de massa depositada em cada filtro

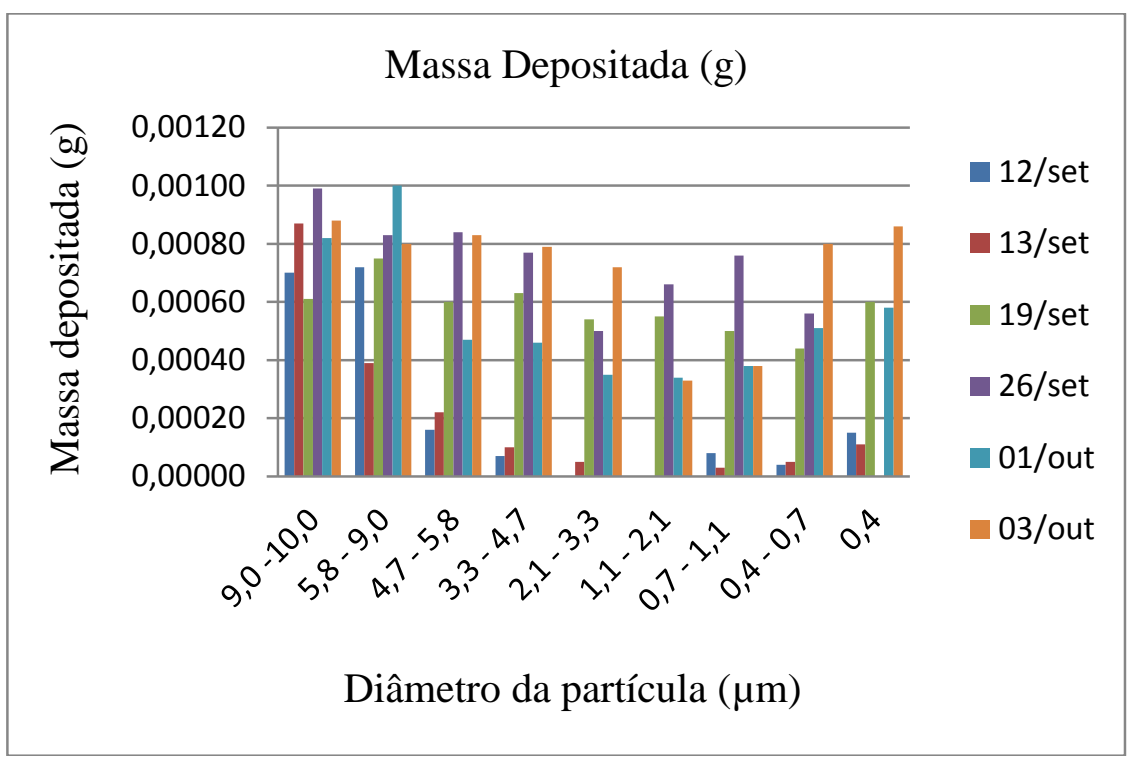

Figura 2: Focos de queimada (A) e trajetória de massas de ar (B) durante 7/09 à 13/09
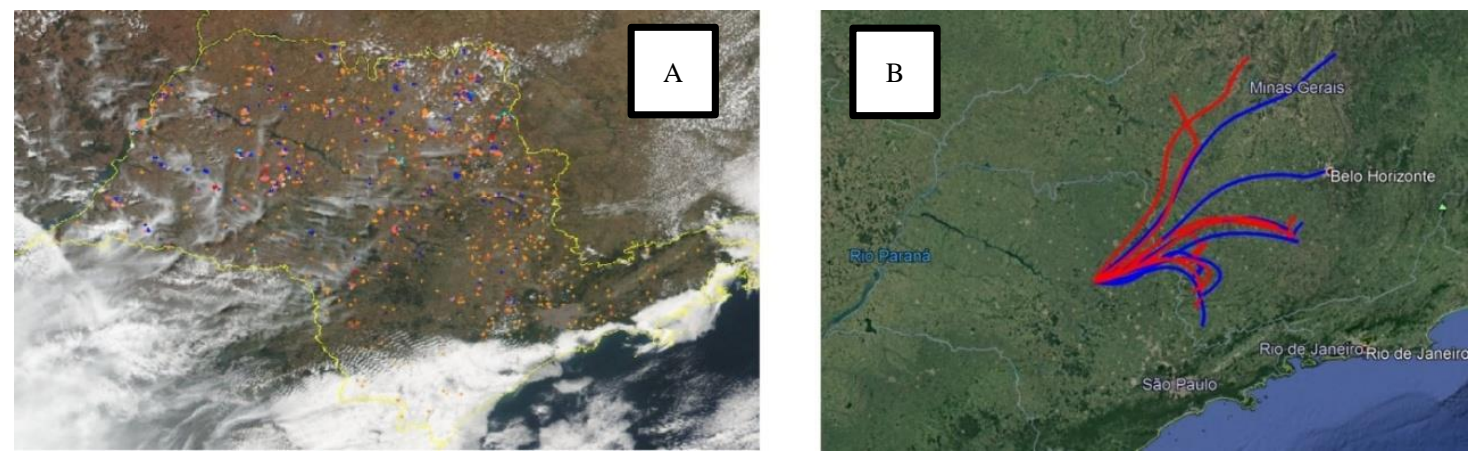

Figura 3: Focos de queimada (A) e trajetória de massas de ar (B) durante 14/09 à 20/09
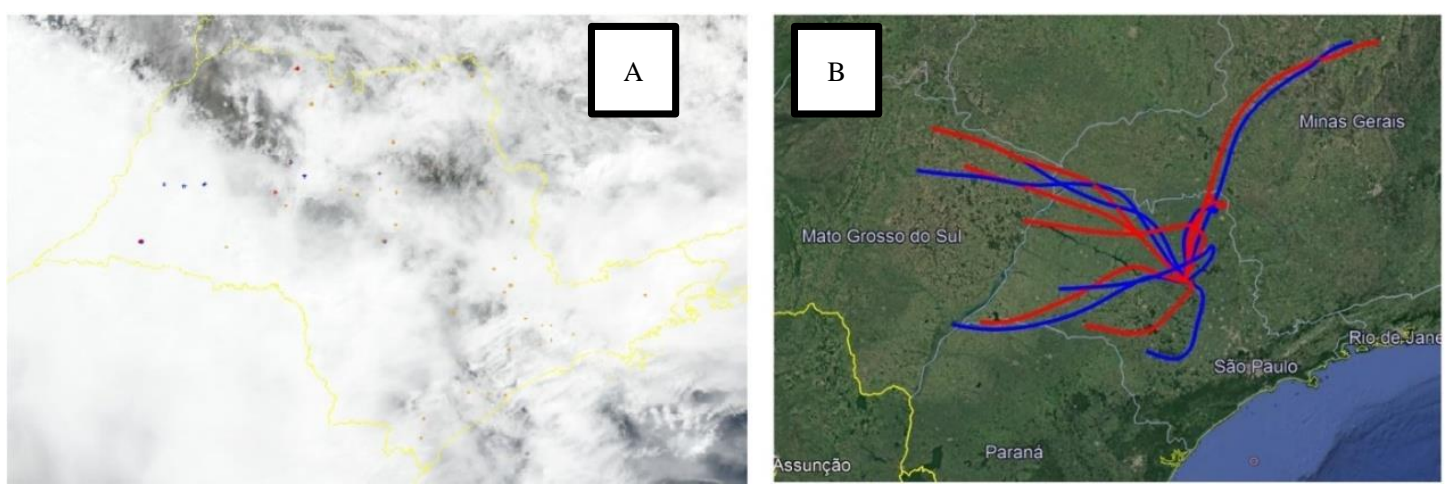


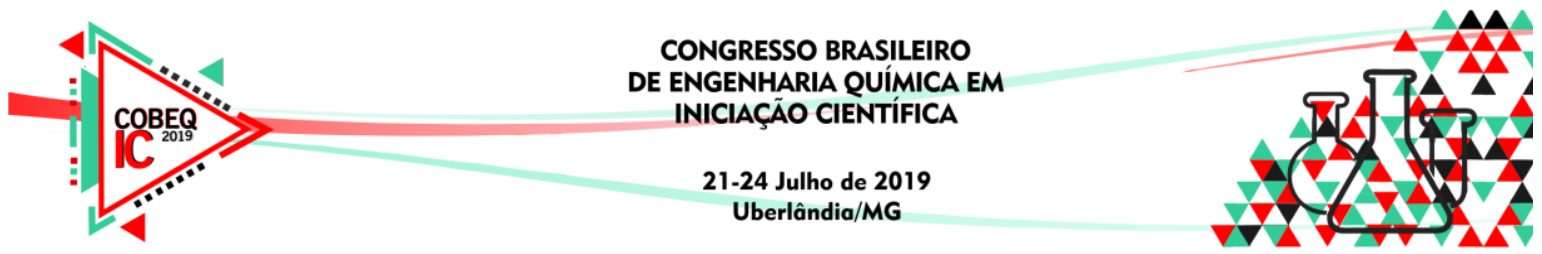

Figura 4: Focos de queimada (A) e trajetória de massas de ar (B) durante 21/09 à 27/09
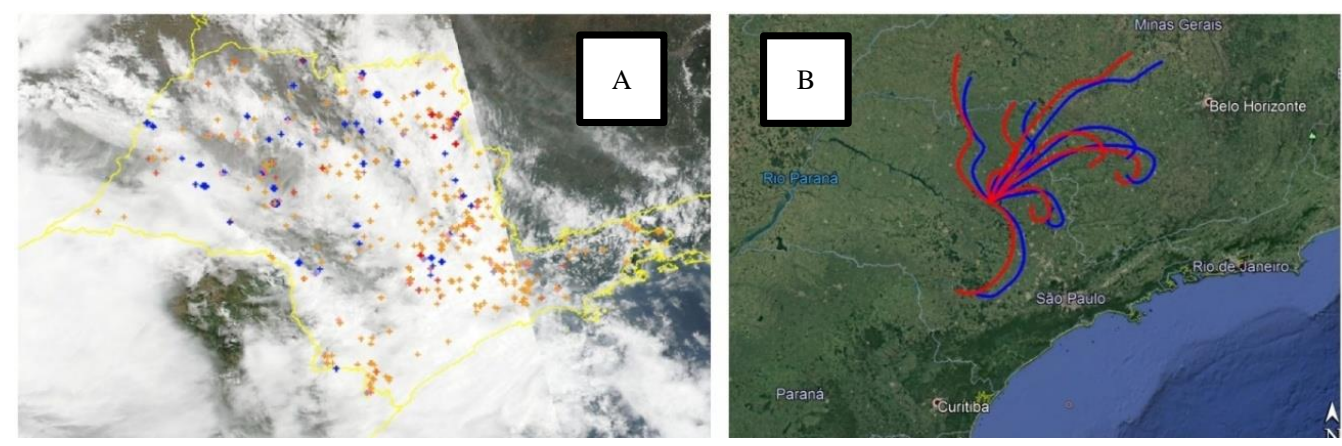

Figura 5: Focos de queimada (A) e trajetória de massas de ar (B) durante 28/09 à 3/10
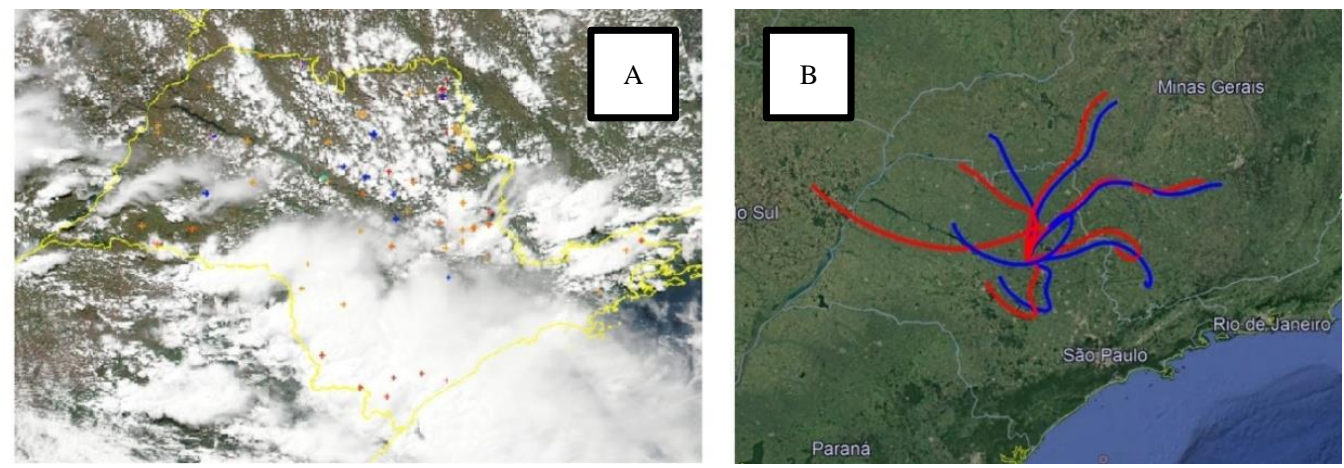

Fonte: Instituto Nacional de Pesquisas Espaciais, NOAA (2019)

Na Tabela 1 são apresentados os números de foco de queimada no Estado de São Paulo e na cidade de Araraquara.

Tabela 1: Número de focos de queimada de acordo com o período

\begin{tabular}{|c|c|c|}
\hline Período & Focos no estado (SP) & Focos em Araraquara \\
\hline $7 / 09$ à $13 / 09$ & 4374 & 22 \\
\hline $14 / 09$ à $20 / 09$ & 145 & 0 \\
\hline $21 / 09$ à $27 / 09$ & 800 & 0 \\
\hline $28 / 09$ à $04 / 10$ & 144 & 2 \\
\hline
\end{tabular}

Fonte: elaborado pelo autor

Na Figura 1, os dias 12 e 13 de setembro apresentaram maiores quantidades em massa de material particulado grosso em relação aos finos. A partir do dia 19/09, a massa depositada para partículas menores que 5,8 $\mu \mathrm{m}$ aumentou consideravelmente comparando-se aos dois primeiros dias de amostragem. No período de 7/09 à 13/09, houve a maior quantidade de queimada em relação aos outros períodos analisados, inclusive no município onde estavam sendo realizadas as amostragens. Nos 14/09 e 27/09 não houve focos de queimadas em Araraquara, porém houve 145 no estado de São Paulo. Os particulados finos, devido ao seu tamanho, são mais facilmente carregados pelas massas de ar na atmosfera, podendo aumentar a concentração dos mesmos em 


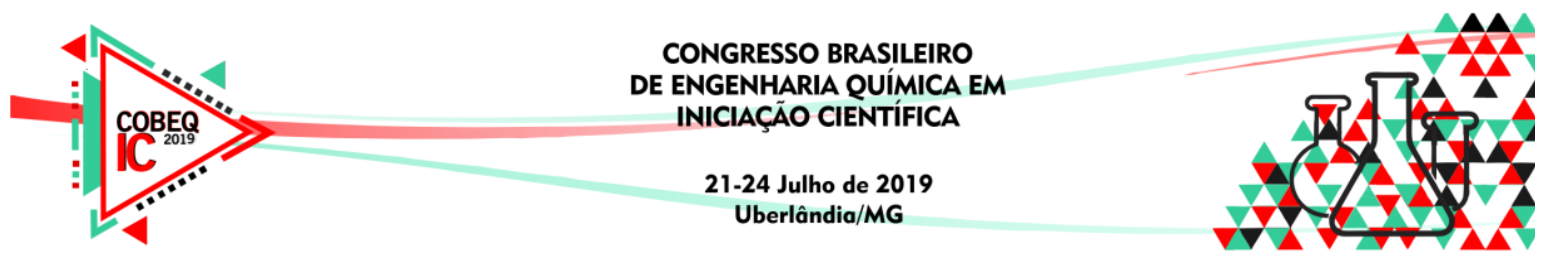

regiões sem queima de biomassa (Fogarin, 2018). Assim, esse pode ter sido um dos fatores para o aumento de particulados finos nesse período. Em contrapartida, o último período de análise (2/09 à 04/10), de acordo com o relatado anteriormente, tiveram 2 focos de queimada em Araraquara e 144 no estado, e apresentou elevadas quantidades em massa de partículas em todos os estágios comparando-se aos outros períodos.

A seguir, na Figura 6 apresenta-se a concentração relativa dos íons acetato, formiato, nitrito, nitrato, sulfato, oxalato, fosfato, amônio, potássio, magnésio e cálcio nos respectivos dias de amostragem.

Figura 6: Concentração relativa em cada amostragem
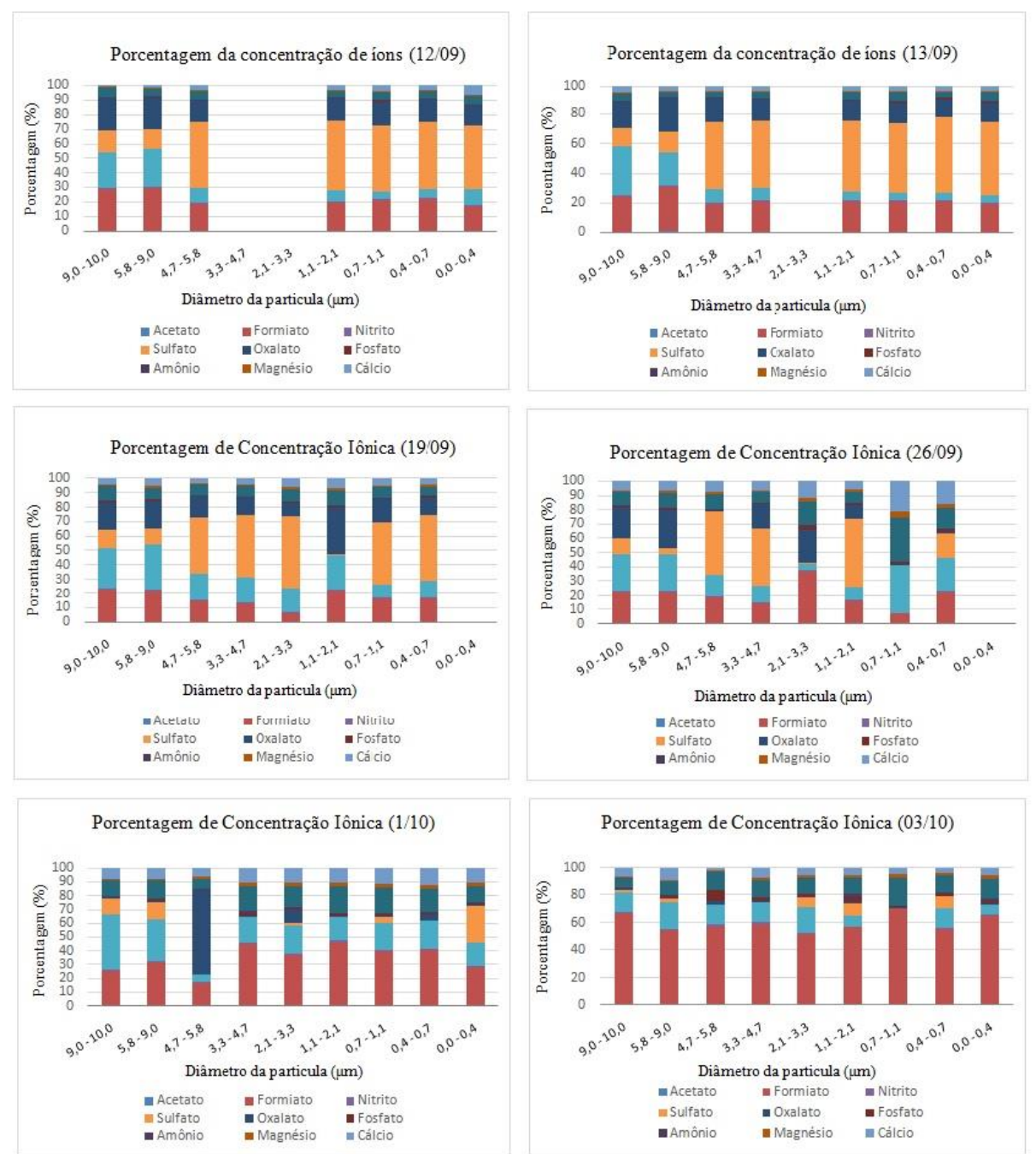

Fonte: elaborado pelo autor

Nos dias 12 e 13 de Setembro, a concentração relativa de sulfato é superior à dos outros íons. O potássio apresenta uma concentração de até $44 \mu \mathrm{g} / \mathrm{m}^{3}$ considerando todos os estágios do impactador, enquanto os íons cálcio e magnésio apresentaram uma concentração mássica muito inferior principalmente em partículas grossas, não caracterizando a ressuspensão de poeira do solo. Nos dias 19 e 16 de Setembro, a maior concentração relativa ainda é a do sulfato e houve um aumento considerável da concentração relativa dos íons oxalato e potássio, este 


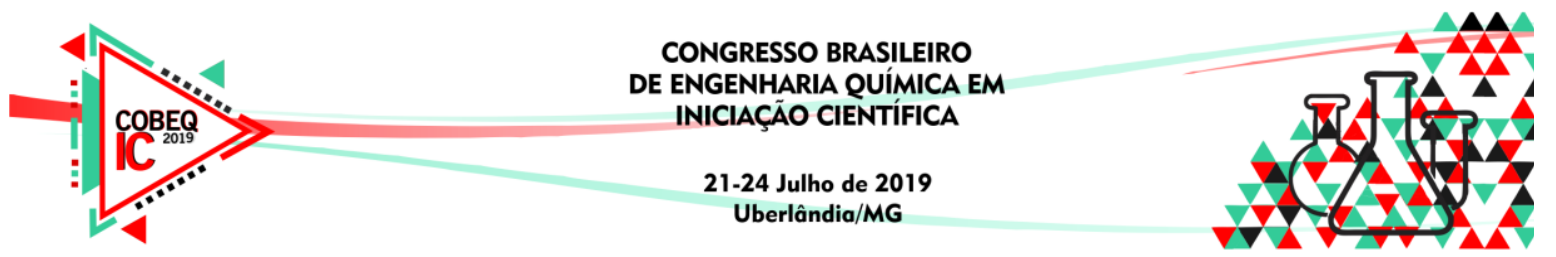

principalmente em partículas menores que $5 \mu \mathrm{m}$, ambos traçadores de queima de biomassa. Enquanto o oxalato é um traçador de partículas grossas, o potássio é indicado em partículas finas.E por fim, nos dias 1 e 3 de Outubro, a concentração de sulfato é muito menor em relação às amostragens anteriores, enquanto as dos íons formiato, acetato, amônio e novamente do potássio são superiores. Pode-se relacionar o aumento do íon amônio com o aumento dos íons acetato e formiato, pela reação de neutralização da amônia com os ácidos que originam esses íons. O íon nitrato apresentou concentração relativa maior em partículas grossas em todas as amostragens, enquanto os íons nitrito e fosfato apresentaram concentrações menores que 1 $\mu \mathrm{g} / \mathrm{m}^{3}$. Com exceção desses dois últimos íons, os apresentados anteriormente apresentam concentração mássica superior quando comparado à amostragens em dias em que não há queima de biomassa, de acordo com Rocha et. Al (2005).

Para fins comparativos, os dados utilizados correlacionam períodos em que há queima de biomassa com períodos em que não há queimadas, considerando a emissão de material particulado de outras fontes, como queima de combustíveis fósseis e indústrias, constante em todos os períodos.

\section{CONCLUSÃO}

Assim, as amostragens ambientais feitas validam as correlações entre o tamanho, concentração e composição química do material particulado assim como apresentam resultados que indicam a influência da queima de biomassa na qualidade do ar, representando a importância desse tipo de análise para relacionar as consequências das atividades antropológicas no meio ambiente e saúde da população.

\section{REFERÊNCIAS}

ALLEN, A. G.; ROCHA, G. O. D.; CARDOSO, A. A. Influence of sugar cane burning on aerosol soluble ion composition in southeastern Brazil. Atmospheric Environment, v. 38, p. 5025-5038. 2004.

FOGARIN, H. M. Avaliação da deposição seca de partículas menores que 2,5 um na zona urbana, agricultura e florestas - Instituto de Química. 2018. $101 \mathrm{f}$. Monografia (Trabalho de Conclusão de Curso em Engenharia Química) - Instituto de Química, Universidade Estadual Paulista, Araraquara, 2018.

ROCHA, G. O. D.; ALLEN, A. G.; CARDOSO, A. A. Influence of Agricultural Biomass Burning on Aerosol Size Distribution and Dry Deposition in Southeastern Brazil. Environ. Sci. Technol., v. 39, n. 14, p. 5293-5301. 2005.

SOUZA, M. D. L. Estudo da distribuição de tamanho e composição iônica de aerossóis e seus efeitos na capacidade de nuclear gotas de nuvens. 2016. 158 f. Tese (Doutorado em Química) - Instituto de Química, Universidade Estadual Paulista, Araraquara, 2016.

VINCENT, J. H. Aerosol Sampling: Science, Standards, Instrumentation and Applications. Hoboken: JohnWiley \& Sons, 2007. 